\title{
Comprehensive Evaluations of Physicochemical Characteristics and Sensory Acceptance of Selected Fruits, Almond and Dark Chocolate Incorporated Yogurt
}

\author{
Mousumi Nath $^{1 *}$, Anika Tasnim ${ }^{1}$, J. M. Kamirul Hasan Chowdhury ${ }^{1}$, Fariha Alam ${ }^{2}$ \\ and Nurul Absar ${ }^{1}$
}

\begin{abstract}
The research aimed to formulate a yogurt mix by combining with natural flavored selected fruits (papaya, apple, banana and mango), almond and dark chocolate for enriched nutritional value and taste. For quality assessment of the yogurt mixture, physicochemical, phytochemical, nutritional and sensory properties were considered. The experimental data of yogurt mix were fitted to 14 models where plain yogurt was used as a control and concomitant $10 \%$ and $20 \%$ yogurt supplements were considered with the mentioned ingredients. The comparative results of all the formulations revealed notable enrichment in yogurt samples compared to the control. Moreover, a significant reduction in lipid content and
\end{abstract}

${ }^{1}$ Department of Biochemistry and Biotechnology, University of Science and Technology Chittagong, Chattogram - 4202, Bangladesh.

${ }^{2}$ Faculty of Biomedical Engineering, Universiti Teknologi Malaysia, Malaysia.

*shimunath@gmail.com

https://orcid.org/0000-0002-4478-9379

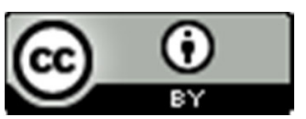

This article is published under the terms of the Creative Commons Attribution 4.0 International License which permits unrestricted use, distribution and reproduction in any medium provided the original author and source are credited.
$\mathrm{pH}$ of the enriched yogurts were observed. In contrast, the fortified yogurt exhibited higher carbohydrate, protein, phenolic and flavonoid contents than the control. Furthermore, the Ash content of all yogurt formulations excluding the yogurt-banana mix was found to be lower than the control and total soluble solids (TSS) were observed to be increased ranging from 10.81 to $15.30 \mathrm{~g}$ per $100 \mathrm{~g}$ of fortified yogurt. Nevertheless, the yogurt fusions conclude that almond-yogurt (AlY20) and mixed-fruits yogurt (MxY20) are the best suitable mix in terms of their acceptability, phytochemical and physicochemical composition.

Keywords: Fruits, Natural fortification, Quality assessments, Sensory analysis, Yogurt.

\section{INTRODUCTION}

Nowadays, healthy habits and nutrition consciousness of consumers have resulted in rising demand for fruits containing high flavonoid content utilizing fortification. Yogurt is a coagulated milk product resulting from the fermentation of lactose in milk by Lactobacillus bulgaricus and Streptococcus thermphilus (Corrieu et al., 2016). The 
popularity of yogurt consumption has gained prominence because of its significant nutritional values, therapeutic effects and nutrient-dense properties. Likewise, it is a rich source of carbohydrates, protein, fat, vitamins, calcium, and phosphorus (Amal et al., 2016). Besides these important properties, yogurt is also easily digested in our bodies.

Fruits are comparatively nutritious and antioxidant-rich, low cost and widely available foods throughout the seasons. Besides, much research has been carried out with an interest in "functional" foods i.e. foods with abundant nutrition which help in more healthiness (Klunklin et al., 2018). In general, the development of organic foods with value-added ingredients has attained a progressive interest in the consumption of dairy products. In the same aspect, organic foods with no chemical pesticides are getting more acceptance attributable to their high nutritious value. Furthermore, valueadded dairy products are manufactured via simple technologies as well as are broadly accepted by people due to proven health benefits, consequently extends importance in the overall dairy market (Krešić et al., 2010). On the contrary, artificial flavors in different food items including yogurt are mostly chemicals which are carcinogenic and believed to have cancer-initiating agent including other health complications. Realizing this, there is a need to explore the use of natural fruit flavors with yogurt aiming not only for flavoring purposes but also for improving valuable nutrients (Otieno, 2009).

In earlier studies, flavors and nutritional values along with tastes of the yogurt have been modified by using the fruits such as papaya, pomegranate, apple, grape, mango banana, etc. and nuts. The above fruits are susceptible to damage due to poor preservative condition, handling, pest attack, disease and deterioration. Also, they cannot be preserved for a long period and hence need to be utilized when they are available during the harvesting season (Nwaoha and Ezeoke, 2019). In this way, the food quality can be improved including reliable preservation techniques for an extended duration. In multiple studies, the use of different passion fruits and other ingredients as flavor in fruit yogurt production was found to improve its nutritional characteristics and sensory properties (Kennas et al., 2020; Karnopp et al., 2017). In the same token, fruits in 
yogurt make the yogurt a tastier and pleasing flavor resulting in broader acceptability in day-to-day life (Islam $e t$ al., 2018; Januário et al., 2017). Similarly, when mixed with fruits, the consistency, viscosity and mouth feel of yogurt are suggestively improved (Karnopp et al., 2017). In another study, it is observed that the combination of yogurt with fruits gives probable prebiotic and probiotic health benefits (Fernandez et al., 2017).

The importance of papaya is endless as it contains carotenoids, essential macro and micro-nutrients and phytochemicals that act as an antioxidant, antimicrobial, anticarminative, anticancer, and has hepato-protective, immunological, and other therapeutic attributes (Saeed et al., 2014). Realizing these benefits, it would be highly anticipated by the consumers to consume papaya enriched yogurt. To this point, a study of yogurt enriched with papaya revealed a maximum consumer satisfaction compared to other selected fruits, for instance, banana and watermelon at various concentration levels (Roy et al., 2015). Nevertheless, the results of the above study also revealed that bananas in yogurt enriched the quality of the yogurt attributable to its excellent source of compounds like vitamins, minerals and carotenoids ( $\beta$-carotene, $\alpha$-carotene, lutein, and zeaxanthin) as reported by Ashokkumar et al. (2018). In the same way, apple is a good source of macro and micro-nutrients and enriched with phytonutrients that have good anti-oxidative properties (Kumar et al., 2018). For that reason, yogurt supplemented with apple has gained prominent acceptability than control yogurt (Bosnea et al., 2016). Furthermore, mango incorporated yogurt was found to be the most preferred refreshing dairy beverage (Ryan et al., 2020; Teshome et al., 2017) which in turn add additional health benefits owing to the amount of vitamin A, C, E, phytochemicals and other important minerals (Fazilah et al., 2018; Freeman et al., 2017).

The main benefit of supplementing almond in yogurt is observed to have enriched protein, dietary fiber, Total Soluble Solids (TSS) content, firmness and viscosity of yogurt. This improvement could be dedicated to almond owing to its excellent and affordable source of vital nutrients as well as proteins, fibers, polyphenols, antioxidants, vitamins and minerals which may play a critical role in preventing disease, lowering 
blood pressure and promoting good health (Eslampour et al., 2020; Yada et al., 2013). In another study, dark chocolates are confirmed as an excellent source of magnesium and iron and chocolate containing $90 \%$ cocoa is believed to be a good source of zinc and selenium that is important for our immune system (Cinquanta et al., 2016). Nevertheless, to the best of the authors' knowledge, there is a lack of evidence concerning yogurt formulations with dark chocolate which is our novel approach.

In the line of the above studies, the objective is the fortification of yogurt with different fruits, dark chocolate as well as almond employing added natural constituents, rather than artificial intending to prioritize on food safety. To formulate the yogurt mix, $10 \%$ and $20 \%$ supplements were considered. Fortified yogurts were evaluated to determine the effect of different fruits, almond and dark chocolate on yogurt in terms of sensory features, phytochemical and physicochemical properties. This study expected that these enriched yogurts might be a great choice in the future for a better taste and enriched nutritional values.

\section{MATERIALS AND METHODS}

\section{Raw Materials}

The milk samples were collected from the local dairy farm. The selected fruits i.e. papaya, apple, banana and mango for supplementation into yogurt were purchased from the local market. Almond and dark chocolate were also collected from the local market of Chittagong Zone, Bangladesh.

\section{Processing of the Fruit Pulp}

To prepare fruit pulp for adding into yogurt, selected fruits were processed using the standard method with slight modification. At first, the fruits were sorted according to their visual quality. Then the fruits were rinsed in warm water. Separate the pulp from the peel. The seeds and the peel were discarded. Finally, the pulps were blended and pasteurized at $70^{\circ} \mathrm{C}$ for 10 mins intended to eliminate pathogens and to extend its shelf life. Likewise, almond and dark chocolate were also blended for supplementation purposes. 


\section{Formulation of Fortified Yogurt}

Yogurt formulation was carried out in the laboratory of the Department of Biochemistry and Biotechnology, University of Science and Technology Chittagong (USTC), Bangladesh. The dairy milk was heated and stirred frequently to avoid burning until the milk reached $82-85^{\circ} \mathrm{C}$ (approximately 20 minutes) and converted into a thick sample so that the pathogens become inactivate. The milk was allowed to cool for inoculation temperature at $42-45^{\circ} \mathrm{C}$ and then inoculation was done with a $10 \%$ yogurt starter culture consisting of Lactobacillus bulgaricus.

At that point, a total of 14 different formulations i.e., two different proportions $(10 \%$ and $20 \%)$ of each ingredient was added into milk. Table 1 shows the quantities of the processed ingredients (fruits, almond and dark chocolate) in the formulation of fortified yogurt. The combined effects of four kinds of fruit pulp on plain yogurts were also evaluated. All types of mixed milk samples were fermented for 24 hours at room temperature for yogurt formation. All varieties of yogurt were prepared in triplicate and each yogurt sample was stored at $4{ }^{\circ} \mathrm{C}$ in the refrigerator until further analysis.

\section{Sensory Evaluation of Formulated Yogurts}

Sensory properties of the different fortified yogurt including the control were measured in terms of various parameters such as colour and appearance, flavor, sourness, body and texture and overall acceptability. Ordinary plain yogurt was used as a control for analysis. Sensory analysis was assessed with 30 participants aged between 20-65 years who were regular consumers of yogurt and also nonallergic to milk beverages. The sensory assessment was carried out twice and the mean values of the sensory evaluation were utilized for calculation (Skarlatos et al., 2020). It is worth noting that the number of consumers is higher than the similar previous sensory analysis studies such as 10 consumers (Kycia et al., 2020), 12 consumers (Mazzaglia et al., 2020). Participants were trained in sensory analysis before their involvement in the evaluation. The sensory evaluation was performed in different sessions maintaining the same time gap after tasting each yogurt sample. Participants evaluated the fourteen different yogurts along with plain yogurt and marked their perceptions using a 9-point hedonic 
Table 1. Proportion of milk and ingredient in the fortified yogurt

\begin{tabular}{clllll}
\hline Milk (\%) & $\begin{array}{l}\text { Amount of } \\
\text { Ingredient (\%) }\end{array}$ & Ratio & Milk (\%) & $\begin{array}{l}\text { Amount of } \\
\text { Ingredient (\%) }\end{array}$ & Ratio \\
\hline 90 & Papaya (10) & $90: 10$ & 80 & Papaya (20) & $80: 20$ \\
90 & Apple (10) & $90: 10$ & 80 & Apple (20) & $80: 20$ \\
90 & Banana (10) & $90: 10$ & 80 & Banana (20) & $80: 20$ \\
90 & Mango (10) & $90: 10$ & 80 & Mango (20) & $80: 20$ \\
90 & Almond (10) & $90: 10$ & 80 & Almond (20) & $80: 20$ \\
90 & Dark chocolate & $90: 10$ & 80 & Dark chocolate & $80: 20$ \\
90 & Mixed (10) & $90: 10$ & 80 & Mixed (20) & $80: 20$ \\
\hline
\end{tabular}

scale (Ghasabnezhad et al., 2019; Hissein et al., 2017). The properties assessed encompassed: 9 = extremely like, $8=$ like very much, $7=$ like moderately, $6=$ like slightly, $5=$ neither like nor dislike, $4=$ dislike slightly, $3=$ dislike moderately, 2 = dislike very much and 1 = extremely dislike. The samples were offered randomly to the participants on ceramic plates.

\section{Physicochemical Composition Analysis}

The $\mathrm{pH}$ of the control and fortified yogurts were measured by the $\mathrm{pH}$ meter using the standard method (AOAC, 2010). In addition, total soluble solids (TSS) were determined by refractometer as degree Brix $\left({ }^{\circ} \mathrm{B}\right)$. The ash content was obtained by drying all yogurt samples using the standard method (AOAC International, 2010). Water-soluble protein was determined by the Folin-Lowry method (Lowry et al., 1951) using BSA (Bovine Serum Albumin) as standard with slight modification. Furthermore, carbohydrate content was estimated using the Anthrone method (Sadasivam and Manickam, 1992) with glucose as standard. Lipid content was measured by the Bligh and Dyer (1959) method.

\section{Phytochemical Composition Analysis}

The presence of phenolic content was determined by slightly modifying the Folin-Ciocalteau method (Ferreira et al., 2007). In brief, $10 \mu \mathrm{L}$ of extracted 
yogurt samples mixed with $990 \mu \mathrm{L}$ distilled water and $50 \mu \mathrm{L}$ of FC (FolinCiocalteu) reagent were added and remained for 5 minutes. Finally, the addition of $150 \mu \mathrm{L}$ of the $20 \%$ sodium carbonate solution lingered for 30 minutes with intermittent shaking for colour development. The absorbance of the resulting blue colour was measured at $760 \mathrm{~nm}$. For analysis purposes, gallic acid was used as a standard and total phenolic content (TPC) was expressed as mg gallic acid equivalents (GAE).

The method referred by Vosoughi et al. (2018) with a slight alteration was adopted to determine the existence of the total flavonoid content of yogurt samples. $1 \mathrm{ml}$ of the sample was mixed with $150 \mu \mathrm{L}$ of $5 \% \mathrm{NaNO}_{2}$ and kept for 5 minutes. Afterward, the mixed solutions were reacted with $300 \mu \mathrm{l}$ of 10 $\% \mathrm{AlCl}_{3}$ and 5 minutes later, $1 \mathrm{ml}$ of $1 \mathrm{~N}$ $\mathrm{NaOH}$ solution was added. Quercetin was used as a standard for the calibration analysis. The absorbance was measured at $520 \mathrm{~nm}$. The total flavonoid content was expressed as $\mathrm{mg}$ quercetin equivalents (QE).

\section{Statistical Analysis}

All analytical studies were done using three replicates to prove the reproducibility of the analysis. Analyzed data were represented as mean \pm standard deviations. Statistical significance of data was evaluated by one-way ANOVA (* indicates $p<0.05$ which is statistically significant).

\section{RESULTS AND DISCUSSION}

In the light of low-cost availability and nutritional value of fruits, almond and dark chocolate, the combinatory effect of these ingredients with yogurt were studied separately at two different percentages mainly $10 \%$ and $20 \%$.

\section{Sensory Analysis}

The sensory evaluation of fortified and control plain yogurts in terms of colour and appearance, flavor, sourness, body and texture and overall acceptability where the mean data for each case are presented in Table 2. The 9-point hedonic scale data for 5 different sensory attributes by all participants are illustrated in Figure 1. The overall results revealed that the sensory evaluation response of participants towards all variations of fortified yogurt was positively related to the addition of ingredients into yogurt compared to control plain yogurt. The scores concerning colour and appearance, flavor, sourness, body 
and texture and overall acceptability were observed to be significantly increased in most of the fortified yogurts than control.

With regards to colour and appearance, all the formulations have a higher value $(\geq 7.03 \pm 0.56)$ than the control $(6.87 \pm 0.97)$ except the dark chocolate-yogurt mix. Additionally, reduced sourness in all fortified yogurt can be witnessed attributable to the sweetness of added ingredients. In particular, the mixed fruits-yogurt blend (MxY20) has the highest acceptance rate of $8.33 \pm 0.66$ due to the lowest sourness whereas it was $4.93 \pm 0.86$ for the control. A similar analysis has been reported by Ryan $e t$ al. (2020) in which mango enriched yogurt showed overall improvement in sensory scores.

Table 2: Sensory evaluation of fortified yogurt with selected fruits, almond and dark chocolate

\begin{tabular}{lccccc}
\hline Samples & $\begin{array}{c}\text { Colour and } \\
\text { appearance }\end{array}$ & Flavor & Sourness & $\begin{array}{l}\text { Body and } \\
\text { texture }\end{array}$ & $\begin{array}{l}\text { Overall } \\
\text { acceptability }\end{array}$ \\
\hline Control & $6.87 \pm 0.97$ & $7.17 \pm 0.59$ & $4.93 \pm 0.86$ & $7.30 \pm 0.53$ & $6.67 \pm 0.66$ \\
PY10 & $7.5 \pm 0.68$ & $7.60 \pm 0.56$ & $6.43 \pm 0.67$ & $7.53 \pm 0.57$ & $7.30 \pm 0.75$ \\
PY20 & $7.67 \pm 0.66$ & $7.93 \pm 0.69$ & $7.47 \pm 0.62$ & $7.93 \pm 0.69$ & $7.60 \pm 0.77$ \\
AY10 & $7.03 \pm 0.56$ & $7.07 \pm 0.69$ & $5.37 \pm 0.61$ & $7.40 \pm 0.77$ & $6.87 \pm 0.51$ \\
AY20 & $7.60 \pm 0.56$ & $7.53 \pm 0.57$ & $6.47 \pm 0.57$ & $7.43 \pm 0.57$ & $7.10 \pm 0.61$ \\
BY10 & $7.23 \pm 0.57$ & $6.73 \pm 0.52$ & $7.23 \pm 0.57$ & $7.80 \pm 0.76$ & $6.73 \pm 0.58$ \\
BY20 & $7.33 \pm 0.61$ & $7.17 \pm 0.53$ & $7.43 \pm 0.62$ & $7.57 \pm 0.73$ & $6.77 \pm 0.62$ \\
MY10 & $7.83 \pm 0.75$ & $8.07 \pm 0.78$ & $7.40 \pm 0.50$ & $8.03 \pm 0.85$ & $7.37 \pm 0.56$ \\
MY20 & $7.90 \pm 0.71$ & $7.87 \pm 0.63$ & $7.50 \pm 0.51$ & $7.83 \pm 0.70$ & $7.80 \pm 0.66$ \\
A1Y10 & $8.63 \pm 0.49$ & $8.43 \pm 0.63$ & $7.53 \pm 0.57$ & $8.67 \pm 0.48$ & $8.60 \pm 0.50$ \\
A1Y20 & $8.87 \pm 0.35$ & $8.93 \pm 0.25$ & $8.17 \pm 0.75$ & $8.77 \pm 0.43$ & $8.77 \pm 0.43$ \\
CY10 & $6.70 \pm 0.70$ & $6.60 \pm 0.85$ & $4.90 \pm 0.92$ & $6.60 \pm 0.72$ & $6.63 \pm 0.61$ \\
CY20 & $6.83 \pm 0.53$ & $6.77 \pm 0.63$ & $5.33 \pm 0.66$ & $6.70 \pm 0.60$ & $6.77 \pm 0.73$ \\
MxY10 & $8.53 \pm 0.57$ & $8.60 \pm 0.50$ & $7.80 \pm 0.76$ & $8.63 \pm 0.49$ & $8.43 \pm 0.57$ \\
MxY20 & $8.70 \pm 0.47$ & $8.87 \pm 0.35$ & $8.33 \pm 0.66$ & $8.77 \pm 0.43$ & $8.70 \pm 0.47$ \\
\hline
\end{tabular}

In this table, means \pm standard deviations $(n=30)$ were displayed and all the values were ranked as 9 point hedonic scale (where " 9 " represents extremely like and " 1 " represents extremely dislike). Control = ordinary plain yogurt; PY10 = Papaya: Yogurt (10: 90); PY 20 = Papaya: Yogurt (20: 80); AY10= Apple: Yogurt (10: 90); AY20 = Apple: Yogurt (20: 80); BY10 = Banana: Yogurt (10: 90); BY20= Banana: Yogurt (20: 80); MY10 = Mango: Yogurt (10: 90); MY20= Mango: Yogurt (20: 80); AlY10= Almond: Yogurt (10: 90); AlY20= Almond: Yogurt (20: 80); CY10 = Chocolate (dark): Yogurt (10: 90); CY20 = Chocolate (dark): Yogurt (20: 80); MxY10 = Mixed: Yogurt (10: 90); MxY20= Mixed: Yogurt (20: 80). 
In conclusion, MxY20 and almond-yogurt (AlY20) were found to be more acceptable compared to other fruits enriched yogurt and control plain yogurt. It is interesting to note that yogurt enriched with dark chocolate (CY10 and CY20) was the least acceptable among all other types of yogurts for the reason that dark chocolate contains more than $80 \%$ cocoa which makes it bitter-taste. Surprisingly, a few participants preferred to have plain yogurt because of the well-known flavor and texture of plain yogurt.

\section{Physico-Chemical Analysis}

The aim was to identify the effect of fruit-supplement in yogurt on the $\mathrm{pH}$ of the yogurt. The comparative performances on $\mathrm{pH}$ are shown in Table 3. The analysis exhibited a significant decrease in $\mathrm{pH}$ for all other fortified yogurt ranging from $4.87 \pm 0.06$ to $5.47 \pm 0.06$ against the control $(5.80 \pm 0.00)$. The lowest $\mathrm{pH}$ value was found to be $4.87 \pm 0.06$ in apple enriched yogurt (AY20) as apple is moderately acidic in contrast to other fruits. Similar findings

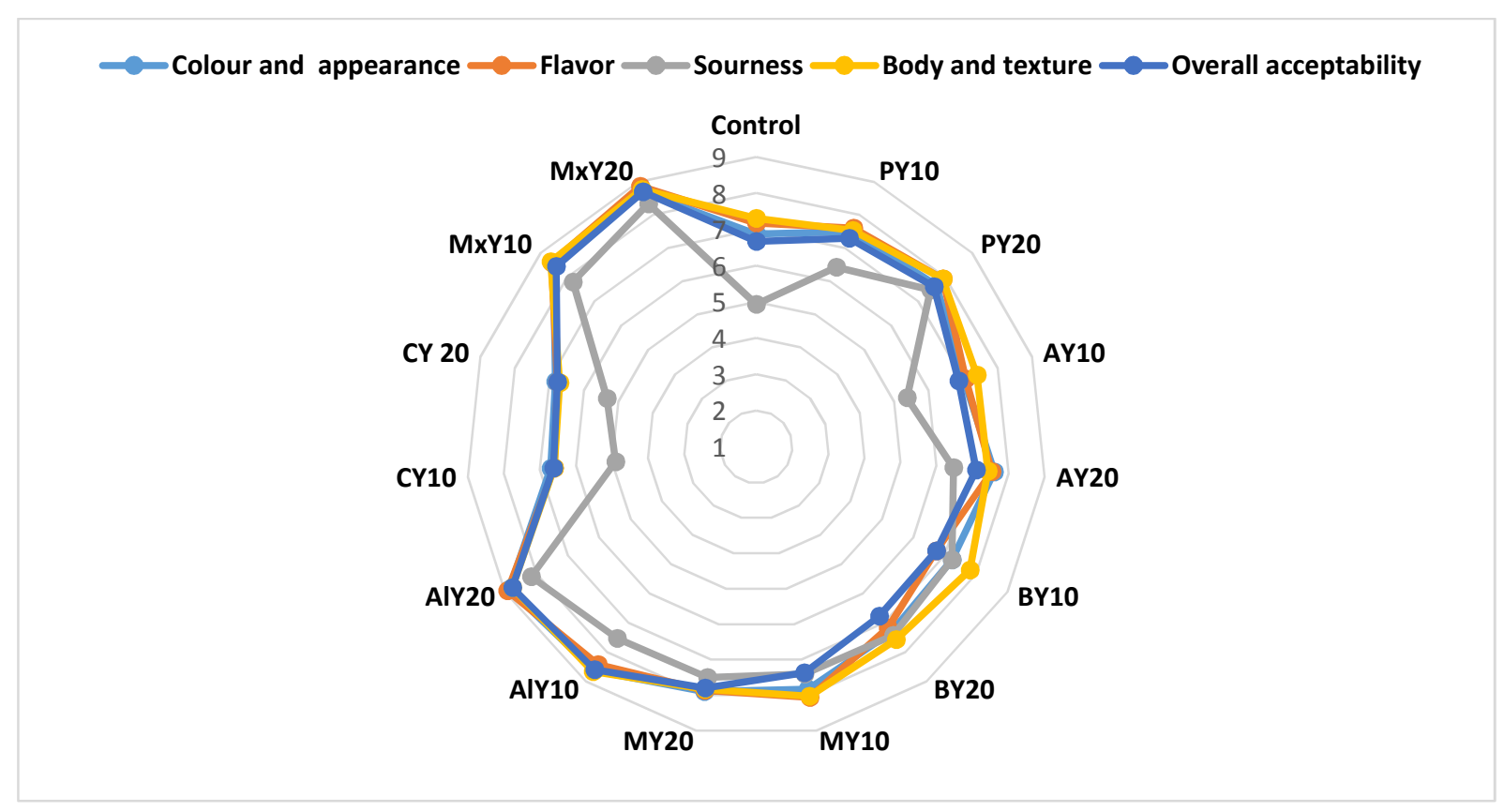

Figure 1. Quantitative sensory analysis of 15 yogurt varieties in 9-point hedonic scale considering the parameters of colour and appearance, flavor, sourness, body and texture and overall acceptability. 
of reduced $\mathrm{pH}$ have been observed with pomegranate and honey fortified yogurt (Kennas et al., 2020) and apple pomace-yogurt mix (Wang et al., 2019) than control yogurt.

Additionally, TSS content for all the yogurt formulations was analyzed. The results exhibited a significant rise in the amount of TSS for fortified yogurts $(\geq 10.58 \mathrm{~g} \pm 0.88)$ as compared to control plain yogurt $(9.50 \mathrm{~g} \pm 0.87)$. As regards the TSS value, the value of control plain yogurt (9.5g) was increased up to $15 \mathrm{~g}$ per $100 \mathrm{~g}$ of yogurt when fruits are added into yogurt. Sigdel et al. (2018) have also obtained similar TSS performance in which they have incorporated mulberry in yogurt.

Furthermore, the impression of fruit-flavored yogurt on proximate compositions, for instance, ash, protein, carbohydrate and lipid contents were analyzed. With regards to ash content, all the formulations were found to have slightly decreased value than the control except banana enriched yogurt.

Table 3. $\mathrm{pH}$ and TSS amount of control and fortified yogurts with selected fruits, almond and dark chocolate

\begin{tabular}{lll}
\hline Samples & pH & TSS $(\mathrm{g} / 100$ g of sample $)$ \\
\hline Control & $5.80 \pm 0.00$ & $9.50 \pm 0.87$ \\
PY10 & $5.40 \pm 0.00^{*}$ & $11.50 \pm 1.00^{*}$ \\
PY20 & $5.37 \pm 0.06^{*}$ & $11.67 \pm 0.76^{*}$ \\
AY10 & $5.10 \pm 0.00^{*}$ & $11.75 \pm 0.43^{*}$ \\
AY20 & $4.87 \pm 0.06^{*}$ & $12.33 \pm 1.26^{*}$ \\
BY10 & $5.17 \pm 0.06^{*}$ & $12.50 \pm 0.50^{*}$ \\
BY20 & $5.37 \pm 0.06^{*}$ & $12.66 \pm 0.58^{*}$ \\
MY10 & $5.20 \pm 0.00^{*}$ & $10.58 \pm 0.88^{*}$ \\
MY20 & $5.30 \pm 0.00^{*}$ & $11.67 \pm 1.44^{*}$ \\
A1Y10 & $5.23 \pm 0.06^{*}$ & $11.83 \pm 0.29^{*}$ \\
A1Y20 & $5.13 \pm 0.06^{*}$ & $12.33 \pm 1.04^{*}$ \\
CY10 & $5.47 \pm 0.06^{*}$ & $14.08 \pm 0.72^{*}$ \\
CY 20 & $5.37 \pm 0.06^{*}$ & $15.00 \pm 0.50^{*}$ \\
MxY10 & $5.40 \pm 0.00^{*}$ & $12.58 \pm 0.14^{*}$ \\
MxY20 & $5.43 \pm 0.06^{*}$ & $12.67 \pm 0.76^{*}$ \\
\hline
\end{tabular}

Results are displayed as means \pm standard deviation, ${ }^{*}$ Significant at $p<0.05$. 
As Table 4 depicts, the ash content of plain yogurt is $0.69 \mathrm{~g}$ whereas bananayogurt formulations have an ash content of $0.76 \mathrm{~g}$ (BY10) and $0.82 \mathrm{~g}$ (BY20) and the rest of the fortified yogurts showed a slight decrease in ash content between $0.53 \mathrm{~g}-0.66 \mathrm{~g}$. A similar performance was reported by Roy et al. (2015) who showed lower ash content in papaya and watermelon containing yogurt than the control yogurt. In a similar context, the study by Hossain et al. (2012) presented higher ash content $(0.80 \mathrm{~g})$ in banana yogurt $(10 \%)$ which also rationalizes our findings.

As regard protein content, it can be seen that a positive correlation exists between added ingredients and improvement in protein content.

Table 4. Proximate composition of control and fortified yogurts with selected fruits, almond and dark chocolate

\begin{tabular}{lcllc}
\hline Samples & Ash & Protein & Carbohydrate & Lipid \\
\hline Control & 0.69 & $2.13 \pm 0.15$ & $4.32 \pm 0.16$ & $2.92 \pm 0.09$ \\
PY10 & 0.61 & $3.44 \pm 0.06^{*}$ & $4.65 \pm 0.17$ & $1.41 \pm 0.24^{*}$ \\
PY20 & 0.66 & $3.67 \pm 0.28^{*}$ & $5.20 \pm 0.13^{*}$ & $1.26 \pm 0.11^{*}$ \\
AY10 & 0.55 & $3.41 \pm 0.22^{*}$ & $4.67 \pm 0.27$ & $1.32 \pm 0.14^{*}$ \\
AY20 & 0.65 & $3.79 \pm 0.13^{*}$ & $5.21 \pm 0.14^{*}$ & $1.20 \pm 0.12^{*}$ \\
BY10 & 0.76 & $3.43 \pm 0.14^{*}$ & $4.59 \pm 0.22$ & $1.63 \pm 0.25^{*}$ \\
BY20 & 0.82 & $3.40 \pm 0.24^{*}$ & $4.74 \pm 0.17^{*}$ & $1.52 \pm 0.28^{*}$ \\
MY10 & 0.53 & $3.13 \pm 0.06^{*}$ & $4.46 \pm 0.16$ & $1.36 \pm 0.26^{*}$ \\
MY20 & 0.55 & $3.40 \pm 0.21^{*}$ & $4.54 \pm 0.14$ & $1.47 \pm 0.10^{*}$ \\
A1Y10 & 0.60 & $2.57 \pm 0.10^{*}$ & $4.81 \pm 0.12^{*}$ & $2.12 \pm 0.18^{*}$ \\
A1Y20 & 0.64 & $4.11 \pm 0.02^{*}$ & $5.17 \pm 0.15^{*}$ & $2.13 \pm 0.27^{*}$ \\
CY10 & 0.56 & $3.35 \pm 0.06^{*}$ & $5.14 \pm 0.13^{*}$ & $1.51 \pm 0.15^{*}$ \\
CY20 & 0.59 & $4.08 \pm 0.05^{*}$ & $5.08 \pm 0.21^{*}$ & $1.32 \pm 0.25^{*}$ \\
MxY10 & 0.58 & $3.46 \pm 0.07^{*}$ & $4.89 \pm 0.17^{*}$ & $1.31 \pm 0.23^{*}$ \\
MxY20 & 0.61 & $3.70 \pm 0.14^{*}$ & $4.97 \pm 0.28^{*}$ & $1.21 \pm 0.14^{*}$ \\
\hline
\end{tabular}

Results are presented as means \pm standard deviation, ${ }^{*}$ Significant at $p<0.05$.

All fruit-flavored yogurt showed significantly higher protein content ranged from $2.44 \mathrm{~g}$ to $4.11 \mathrm{~g}$ as opposed to $2.13 \mathrm{~g}$ in the case of plain control yogurt. The highest protein content was detected in AlY20 (4.11g) compared to other fortified yogurts and that may be because of the high protein content in 
almond itself. Therefore, the higher value in the protein content of fruitflavored yogurts could be attributed due to the addition of fruits with increased nutritional value and, a similar finding has been observed by Othman et al. (2019).

Likewise, supplementation of different types of fruit pulp, almond and dark chocolate in yogurt is realized to have a positive influence in the carbohydrate content of all varieties of fortified yogurt. Table 4 suggests increased carbohydrate contents in enriched yogurt which could be attributed to high carbohydrate content in these foodstuffs. These findings are consistent with the investigations done by Karnopp et al. (2017) and Amal et al. (2016) where the addition of fruits has increased the carbohydrate content of fortified yogurt.

Additions of varieties of fruits, dark chocolate and almond have a significant influence on the fat content of the yogurt. From Table 4, it can be concluded that the fat content in control $(2.92 \mathrm{~g})$ can be reduced ranging from $2.13 \mathrm{~g}$ to $1.20 \mathrm{~g}$ in the case of formulations containing fruits, almond and dark chocolate. Similar observations were also reported by Roy et al. (2015).

\section{Phytochemical Analysis}

Table 5 demonstrates the quantitative phytochemical analysis of control and fortified yogurts. It is evident from the presented data that fruits, almonds and dark chocolates have a significant influence on total phenolic and flavonoid content when they are blended with yogurt. The total amount of phenol and flavonoid were pointedly increased in fortified yogurt compared to control yogurt. As a result, these varieties of fortified yogurts could be considered as a rich dietary source of polyphenols and flavonoids like bioactive compounds. A related study reported by Kim et al. (2020) concluded that basil seed gum supplementation improved the total phenol and flavonoid content in yogurt. Other research conducted by Karaaslan et al. (2011) showed that grape and white dragon fruit advanced the total phenolic content in yogurts, respectively. Further to conclude, dark chocolate and apple supplemented yogurt showed higher phenolic content $86.44 \pm 4.38 \mathrm{mg}$ (CY20) and 89.87 \pm 3.09 mg (AY20), respectively. As regard flavonoid content, a higher value was 
obtained in almond and apple has presented the formulation of yogurt supplemented yogurt i.e., AlY20 blends combining with numerous $(204.71 \pm 9.80 \mathrm{mg})$ and AY20 $(193.71 \pm 10.10 \mathrm{mg})$. selected fruits, almond, dark chocolate and mixed fruits. The obtained results of all 14 formulations and control demonstrated that the production of yogurt fraternized with selected fruits

With the strong motivation and other ingredients substantially towards enriched nutrition and the healthiness of consumers, this study

Table 5: Phytochemical analysis of control and fortified yogurts with selected fruits, almond and dark chocolate

\begin{tabular}{lll}
\hline Samples & Total Phenolic Content & Total Flavonoid Content \\
\hline Control & $41.91 \pm 6.38$ & $118.02 \pm 11.66$ \\
PY10 & $72.5 \pm 8.43^{*}$ & $155.56 \pm 8.03^{*}$ \\
PY20 & $78.36 \pm 5.00^{*}$ & $147.3 \pm 5.06^{*}$ \\
AY10 & $75.27 \pm 4.92^{*}$ & $178.46 \pm 10.07^{*}$ \\
AY20 & $89.87 \pm 3.09^{*}$ & $193.71 \pm 10.10^{*}$ \\
BY10 & $58.58 \pm 9.35$ & $175.43 \pm 9.66^{*}$ \\
BY20 & $79.77 \pm 6.96^{*}$ & $189.23 \pm 6.23^{*}$ \\
MY10 & $73.47 \pm 8.79^{*}$ & $169.38 \pm 4.39^{*}$ \\
MY20 & $82.59 \pm 5.63^{*}$ & $175.33 \pm 6.82^{*}$ \\
ALY10 & $76.77 \pm 5.90^{*}$ & $187.67 \pm 5.06^{*}$ \\
ALY20 & $79.72 \pm 5.50^{*}$ & $204.71 \pm 9.80^{*}$ \\
CY10 & $80.43 \pm 5.37^{*}$ & $135.88 \pm 6.09$ \\
CY 20 & $86.44 \pm 4.38^{*}$ & $147.09 \pm 8.75^{*}$ \\
MXY10 & $78.27 \pm 4.54^{*}$ & $165.07 \pm 7.20^{*}$ \\
MXY20 & $81.60 \pm 2.17^{*}$ & $181.45 \pm 11.12^{*}$ \\
\hline
\end{tabular}

Results are shown as means \pm standard deviation, ${ }^{*}$ Significant at $p<0.05$.

improved the physicochemical and sensory properties compared to the control. It was witnessed that the best acceptability was attained in the case of
$20 \%$ supplement. Besides this, the nutritional values such as carbohydrate and protein were observed to be enriched in fortified yogurts. However, 
comparatively lesser fat contents are observed in all formulations than the control. Following the qualitative sensory analysis, almond-yogurt and mixed fruits-yogurt are realized to be highly appealing over other combinations. In further analysis, it was observed that the phytochemicals of fortified yogurts for instance phenolic and flavonoid contents were significantly improved. Therefore, it can be concluded that the yogurt incorporated with selected fruits, almond and dark chocolate is a rich source of nutrition and capable of satisfying consumers' interest. Because of the above findings of the formulated yogurt with enriched sensational and other functional properties, it would be favorably recommended to commence flavor additives which may stimulate the commercialization of yogurt with other functional ingredients in the local and international markets.

\section{ACKNOWLEDGMENT}

The authors wish to thank the University of Science and Technology Chittagong, Bangladesh to provide the laboratory and technical support in this project.

\section{REFERENCES}

Amal, AM., Eman A.M. and Zidan N.S. (2016). Fruit flavored yoghurt: chemical, functional and rheological properties. International Journal of Environmental and Agriculture Research (IJOEAR), 2(5).

AOAC. (2010). Association of official analytical chemists. Official Method of Analysis, 19th Edition, Washington, DC.

AOAC International (2010). Official methods of analysis of aoac international. Association of Analytical Chemists, 18th edition. Gaithersburg, Maryland, USA.

Ashokkumar, K., Elayabalan, S., Shobana, G., Sivakumar P. and Pandiyan, M. (2018). Nutritional value of cultivars of Banana (Musa spp.) and its future prospects. Journal of Pharmacognosy and Phytochemistry, 7(3): 2972-2977.

Bligh, E.G. and Dyer, W.J. (1959). A rapid method of total lipid extraction and purification. Canadian Journal of Biochemistry and Physiology, 37(8): 911-917.

Bosnea, A.L., Kopsahelis, N., Kokkali, V., Terpou, A. and Kanellaki, M. (2016). Production of a novel probiotic yogurt by incorporation of L. casei enriched fresh apple pieces, dried raisins and wheat grains. Food and Bioproducts Processing, 102: 6271.

Cinquanta, L., Cesare, C.D., Manoni, R., Piano, A., Roberti, P., Salvatori G. 
(2016). Mineral essential elements for nutrition in different chocolate products. International Journal of Food Sciences and Nutrition, 67(7): 16.

Corrieu, G. and Béal, C. (2016). Yogurt : the product and its manufacture. Encyclopedia Food Health, 5: 617-624.

Eslampour, E., Asbaghi, O., Hadi, A., Abedi, S., Ghaedi, E., Lazaridi, A.V. and Miraghajani, M. (2020). The effect of almond intake on blood pressure: A systematic review and meta-analysis of randomized controlled trials. Complementary Therapies in Medicine, 50: 102399.

Fazilah, N.F., Ariff, A.B., Khayat, M.E., Solis, L.R. and Halim, M. (2018). Influence of probiotics, prebiotics, synbiotics and bioactive phytochemicals on the formulation of functional yogurt. Journal of Functional Foods, 48: 387-399.

Fernandez, M.A. and Marette, A. (2017). Potential health benefits of combining yogurt and fruits based on their probiotic and prebiotic properties. Advanced Nutrition, 8:155S-64S.

Ferreira, I.C.F.R., Baptista, P., Vilas, B.M. and Barros, L. (2007). Free radical scavenging capacity and reducing power of wild edible mushrooms from northeast Portugal: Individual cap and stipe activity. Food Chemistry, 100: 15111516.

Freeman, B.M.B., Sandhu, A.K. and Edirisinghe, I. (2017). Mangos and their bioactive components, adding variety to the fruit plate for health. Food and Function, 8(9): 3010-3032.

Ghasabnezhad, M., Hojjati, M. and Jooyandeh, H. (2019). Effects of soluble soybean polysaccharides on properties of kefir produced from cow and buffalo milks. Applied Food Biotechnology, 7(1): 31-40.

Hissein, F.H., Razavi, S.H. and Djomeh, Z.E. (2017). Physicochemical properties and sensory evaluation of reduced fat fermented functional beef sausage. Applied Food Biotechnology, 4(2), 93-102.

Hossain, M.N., Fakruddin, M., Islam, M.N. (2012). Quality comparison and acceptability of yoghurt with different fruit pulps. Journal of Food Processing and Technology, 3(171).

Islam, M., Akter, F., Aziz, M. and Uddin, M. (2018). Development of probiotic milk drinks using probiotic strain isolated from local yogurt. Fundamental and Applied Agriculture, 3(2): 446-452.

Januário, J.G.B., Silva, I.C.F.D., Oliveira, A.S.D., Oliveira, J.F.D., Dionísio, J.N., Klososki S.J. and Pimentel. T.C. (2017). Probiotic yogurt flavoured with organic beet with carrot, cassava, sweet potato or corn juice: physicochemical and texture evaluation, probiotic viability and acceptance. International Food Research Journal, 24: 359- 366.

Karaaslan, M., Ozden, M., Vardin, H., and Turkoglu, H. (2011). Phenolic fortification of yogurt using grape 
and callus extracts. LWT - Food Science and Technology, 44 (4): 10651072.

Karnopp, A.R., Oliveira, K.G., Andrade, E.F.D., Postingher, B.M., and Granato, D. (2017). Optimization of an organic yogurt based on sensorial, nutritional, and functional perspectives. Food Chemistry, 233: 401-411.

Kennas, A., Chibane, A.H., Kessal, F. and Halladj, F. (2020). Effect of pomegranate peel and honey fortification on physicochemical, physical, microbiological and antioxidant properties of yogurt powder. Journal of the Saudi Society of Agricultural Sciences, 19(1): 99-108.

Kim, S.Y., Hyeonbin, O., Lee, P. and Kim, Y.S. (2020). The quality characteristics, antioxidant activity, and sensory evaluation of reducedfat yogurt and non-fat yogurt supplemented with basil seed gum as a fat substitute. Journal of Dairy Science, 103(2): 1324-1336.

Klunklin, W. and Savage, G. (2018). Physicochemical properties and sensory evaluation of wheat-purple rice biscuits enriched with greenlipped mussel powder (perna canaliculus) and spices. Journal of Food Quality, 1-9.

Krešić, G., Herceg, Z., Lelas, V. and Jambrak, A.R. (2010). Consumers' behaviour and motives for selection of dairy beverages in Kvarner region, a pilot study. Mljekarstvo, 60: 50-58.
Kumar, P., Sethi, S., Sharma, R.R., Singh, S., Saha, S., Sharma, V.K., Verma, M.K. and Sharma, S.K. (2018). Nutritional characterization of apple as a function of genotype, Journal of Food Science and Technology, 55(7): 2729-2738.

Kycia, K., Śmigielb, A.C., Szydłowskac, A., Sokółd, E., Ziarnod, M. and Gniewoszb, M. (2020). Pullulan as a potential enhancer of Lactobacillus and Bifidobacterium viability in synbiotic low fat yoghurt and its sensory quality. LWT-Food Science and Technology, 128: 109414.

Lowry, O.H., Rosebrough, N.J., Farr, A.L. and Randall, R.J. (1951). Protein measurement with the Folin phenol reagent. Journal of Biological Chemistry, 193(1): 265-275.

Mazzaglia, A., Legarová, V., Giaquinta, R., Lanza, C.M., Restuccia, C. (2020). The influence of almond flour, inulin and whey protein on the sensory and microbiological quality of goat milk yogurt. LWT-Food Science and Technology, 128: 109138.

Nwaoha, I.E.M. and Ezeoke, A.M. (2019). Production and quality evaluation of yoghurt enriched with two accessions of passion fruits (Passiflora edulis f. flavicarpa). Asian Food Science Journal, 10(1): 1-24.

Othman N., Hamid, H.A. and Suleiman, N. (2019). Physicochemical properties and sensory evaluation of yogurt nutritionally enriched with papaya. Food Research, 3(6): 791-797. 
Otieno, W.A. (2009). Production of an acceptable cultured sour milk flavoured with a blend of passionpapaya pulps. BSc project, (University of Nairobi, Kenya).

Roy, D.K.D., Saha, T., Akter, M., Hosain, M., Khatun, H. and Roy, M.C. (2015). Quality evaluation of yogurt supplemented with fruit pulp (Banana, Papaya, and Water Melon). International Journal of Nutrition and Food Science, 4(6): 695699.

Ryan, J., Hutchings, S.C., Fang, Z., Bandara, N., Gamlath, S., Ajlouni, S. and Ranadheera C.S. (2020). Microbial physico-chemical and sensory characteristics of mango juice-enriched probiotic dairy drinks. International Journal of Dairy Technology, 73: 182-190.

Sadasivam, S. and Manickam, A. (1992). Biochemical Methods for Agricultural Sciences. Wiley Eastern Ltd., New Delhi, 6-7.

Saeed, F., Arshad, M.U., Pasha, I., Naz, R., Batool, R., Khan, A.A., Nasir, M.A. and Shafique, B. (2014). Nutritional and phyto-therapeutic potential of papaya (Carica Papaya Linn): an overview. International Journal of Food Properties, 17: 6371653.

Sigdel, A., Ojha, P. and Karki, T.B. (2018). Phytochemicals and syneresis of osmo-dried mulberry incorporated yogurt. Food Science \& Nutrition, 6(4): 1045-1052.
Skarlatos, L., Marinopoulou, A., Petridis, D. and Raphaelides, S.N. (2020). Texture assessment of set yogurt using sensory and instrumental methods. International Dairy Journal, 104:104644.

Teshome, G., Keba, A., Assefa, Z., Gebre, B. and Esho, F. (2017). Development of fruit flavored yoghurt with mango (Mangifera indica L.) and papaya (Carica papaya L.) fruits juices. Food Science and Quality Management, 67: 40-45.

Vosoughi, N., Gomarian, M., Pirbalouti, A.G., Khaghani, S. and Malekapoor, F. (2018). Essential oil composition and total phenolic, flavonoid contents, and antioxidant activity of sage (Salvia officinalis L.) extract under chitosan application and irrigation frequencies. Industrial Crops and Products, 117: 366-374.

Wang, X., Kristo, E. and LaPointe, G. (2019). The effect of apple pomace on the texture, rheology and microstructure of set type yogurt. Food Hydrocolloids, 91: 83-91.

Yada, S., Huang, G. and Lapsley, K. (2013). Natural variability in the nutrient composition of Californiagrown almonds. Journal of Food Composition and Analysis, 30: 80-85. 